\title{
翏
}

PHYSICAL EDUCATION, FITNESS AND SPORTS

\section{The prevention of overtraining with the monitoring training loads: case of football}

Received 07 July 2019

Accepted 01 September 2019

www.ijpefs.com

\section{Zeghari Lotfi a, , Moufti Hicham a, Arfaoui Amine a, Habki Yassir a}

a Royal Institute for Managerial Training in Youth and Sport, Morocco

*Corresponding Author Email: zegharilotfi@gmail.com

Abstract: The aim of this paper is to use a training load quantification tool (RPE) to evaluate if the training load programmed by the coach is appropriate to the characteristics of these footballers. The study was conducted at the football section of the Sale Sports Association, Morocco, on a sample of 8 football players who practice in the club of the Association, aged between 18 and 21 years, the study was established during a mesocycle in a period from $18 / 03 / 2019$ to 20/04/2019. For the quantification of the training load (TL) we chose the (RPE) tool, where each footballer must give his own perception of the effort felt in each training session, taking into consideration also the duration of the session. This will allow us to calculate the intensity of the session estimated, on a scale from 0 to 10 . Based on the results of the quantification of training load for the 8 footballers, we note that in the majority of the cases, the acute load (AL) is higher than the chronic load (CL) at the end of each week. On the other hand, for the monotony index (MI) that provides information on the negative adaptations of training and overtraining, we note that it present a high value among the majority of footballers $(1.8 \mathrm{UA}<\mathrm{MI}<2.1 \mathrm{UA})$. For the average of the ratio of the training load: acute/chronic, we note that for the first three footballers the training loads are higher compared to the others. The monitoring training load help to better conceptualize the adaptations of the athlete to the training, and also allows the prediction of the performance.

Key Words: Morocco, Training loads, Football, Injuries, Overtraining

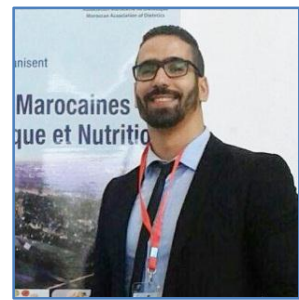

Dr. Zeghari Lotfi received his PhD at the University of Ibn Tofail in Kenitra - Morocco. He joined the Royal Institute of Managerial Training as an associate-professor in 2018, where he taught several subjects related to sports science, nutrition and the supervision of research projects. He is specialized in nutrition, health, and sports training. In his career as a researcher he has published several works in relation with the fields mentioned above and in connection with sports, nutrition and chronic diseases such as diabetes and obesity.

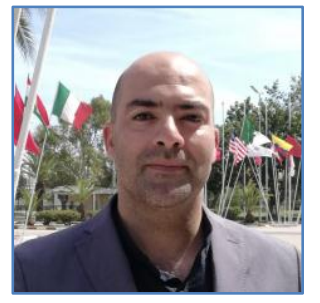

Professor Hicham Moufti is a researcher in sports sciences, holds a master's degree (STAPS) from the University of Caen, and then obtained his doctorate in science and techniques of physical activity and sports (STAPS) in the same University. Since October 2008 he is an Associate Professor at the Royal Institute for Managerial Training, salé, Morocco, where he has also been in charge of the programming, the accreditation and implementation of training content in bachelor's and master's degrees in sports science. His research interests includes Biomechanics, Characterization and analysis of the phenomena inherent to sports technology, Training planning and Measurement and physical tests.

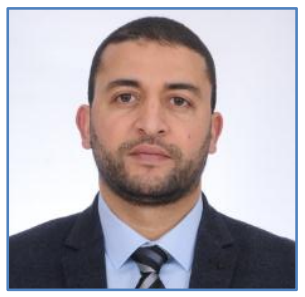

Dr. Amine Arfaoui, obtained his PhD from Ibn Tofail University of Kenitra in the field of biological and medical sciences in 2008. At present he serve as a Deputy Director for pedagogical affairs at Royal Institute of Managerial Training. Amine is specialized in biostatistics and epidemiology and his research focuses on data analysis for health topics.

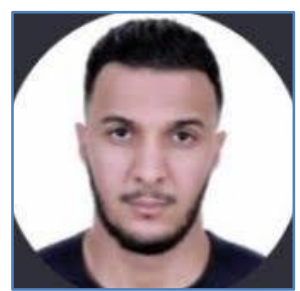

Yassir HABKI is a graduate of the Royal Institute of Managerial Training. He has a long and successful career as a soccer player of more than 7 years in the sports association of Sale. Furthermore, he has participated in several soccer games along with his team on the national and international level as well as represented his school in the national universities' competition. 


\section{Zeghari Lotfi et al.,/2019}

\section{Introduction}

Professional football, like any high-level sport, imposes significant training loads on the athlete. This solicitation can partly explain the high incidence of injuries reported in the literature [1]. However, the risk of injuries can be limited through prevention programs based on the proper training schedule. [2] Fatigue and poor recovery are two essential markers that the coach must consider in order to optimize performance, avoiding overtraining and injuries. [3] The monitoring of training loads is an essential tool for: determining the degree of adaptation of the athlete with the load programmed during the training, understanding the individual reactions to the program, and also for determining the state of fatigue, [4] which will allow the trainer to predict the recovery time necessary to minimize the risk of overtraining, leading in many cases to non-functional disease [5].

There are several ways to quantify the training load (internal or external), among these tools we quote those that correspond to the characteristics of the exercise (intensity, volume ...) [6] for example, the total distance covered in a race, the total training time and the percentage of a maximum repetition (MR), but also there are new technological tools such as accelerometer, GPS and power sensors [7]. Other types of tools make it possible to take into account the feeling of the athlete, otherwise known as the internal training charge, which represents all the acute and chronic adaptations of the body with respect to the external load [7]; like the RPE (Rate Perceived Exertion). The aim of this study is to use a training load quantification tool (RPE) developed by Borg in 1998 [8], to evaluate if the training load programmed by the coach is appropriate to the characteristics of these footballers, and also highlight the importance of using this tool in programming a tailored and specific training to prevent injuries or overtraining in general.

\section{Material and methods:}

\subsection{Sample}

The study was conducted at the football section of the Sale Sports Association, Morocco, on a sample of 8 football players who practice in the club of the Association, aged between 18 and 21 years, who play in the national championship in Morocco, this athletes were chosen according to precise standards (commitment, seriousness, tenure), the study was established during a mesocycle in a period from $18 / 03 / 2019$ to $20 / 04 / 2019$.

\subsection{Protocol}

For the quantification of the training load (TL) we chose the (RPE) tool, where each footballer must give his own perception of the effort felt in each training session, taking into consideration also the duration of the session. This will allow us to calculate the intensity of the session estimated, on a scale of 0 to 10 , after asking the following question to the 8 athletes' after 15 minutes of the session «How did you feel about the session?"

Based on the responses of each athlete on the feeling questionnaire, we can calculate at the following variables:

\subsection{ALCL}

The Ratio Acute Load/Chronic load [5] measures the relationship between acute load (load of the current week) and chronic load (average load of the last 4 weeks). The monitoring of the RCAC preserves the training load in the high load/low risk zone. When the ratio is too low $(<0.8)$ or too high $(\geq$ $1.5)$, the risk of injury increases significantly and the load needs to be adjusted.

\subsection{Acute Charge (AC)}

Represent the cumulative charge for a current week. Usually, the higher the acute load (compared to the chronic load), the more tired the athlete is. In some cases, the acute load can also be calculated over shorter periods.

\subsection{Chronic load (CL)}

Represents the weekly load (Load = duration $\mathrm{x}$ RPE) is the moving average of the last 4 weeks. Normally, the higher the chronic load, the more fit the athlete is. 


\section{Zeghari Lotfi et al.,/2019}

\subsection{Monotony}

The Monotonic Index proposed by American scientist Dr. Carl Foster [9] measures the variation in daily workload during the week. A high training load related to a monotonicity index greater than 2 is a significant risk factor for injury, and health problems related to overtraining. [9]

\subsection{Duration}

Duration of the training session in (Min).

\subsection{The training load (TL)}

The training load in arbitrary units (AU) refers to the combination of sports and non-sport stressors (training, competition, work, social life, family, studies, etc.) which affect the athlete [10]. The workload can be divided into two types: external load and internal load.

\subsection{Statistical analysis}

The data entered and analyzed using Excel version 2016.

\section{Results}

\subsection{Monitoring of training load for each footballer}

Figures from 1 to 8 correspond to the evolution of the training load monitoring parameters for the 8 football players during a period of 29 days. The axis to the left corresponds to the Chronic load (CL), and the Acute Charge (TL) in (UA), and the second Vertical Axis to the right corresponds to the values of Monotonicity and the ALCL in UA.

According to figure 1, we see that in the first week the curve of the CL generally exceeds the curve of the AL, also in the second week, except that from the $12^{\text {th }}$ until the $16^{\text {th }}$ day, we notice that the $\mathrm{AL}$ is superior than the CL, and this is the case for the end of the $3^{\text {rd }}$ and $4^{\text {th }}$ week, which explains that at the end of each week the players and more and more tired, and risk of injuries.

The monotonicity index provides information on negative adaptations of training and overtraining, according to the figure we note that it is high in this athlete (1.8UA < $\mathrm{MI}<2.1 \mathrm{UA})$. According to Figure 3, we notice for the third player, three periods of excessive fatigue, this is where the AL exceeds the CL, the first from the $4^{\text {th }}$ until the $8^{\text {th }}$ day of the first week, the second is from $12^{\text {th }}$ at the $15^{\text {th }}$ day, as well as the last is from the $18^{\text {th }}$ to the $20^{\text {th }}$ day. From Figure 3 , the $\mathrm{AL}$ is the most dominant, since it appears from the $4^{\text {th }}$ day of the first week to the middle of the second week, then it begins to decrease gradually, with an increase in the CL in the third and fourth week. From Figure 4 we note that the CL exceeds the AL in the beginning and the middle of the weeks, while the CL decreases in the weekend followed by an increase in the $\mathrm{AL}$, as well a remarkable increase at the level of the ALCL in the $4^{\text {th }}$ week, also a monotonic index very high $(1.8<\mathrm{MI}$ $<2.2$ ). According to Figure 5, the fifth player had 4 training load peaks (CL), $7^{\text {th }}, 14^{\text {th }}, 21^{\text {st }}$ and $28^{\text {th }}$. In subjects 6,7 and 8 the $A L$, exceeds the CL at the end of each week.

\subsection{The comparison of the training loads of the 8 footballers over the four weeks}

The figure below illustrates the sum of the training load observed for the 8 footballers over a period of 4 weeks. This type of presentation offers good visibility of the principle of progressivity of the load, which is a fundamental concept in order to increase the training load and minimizing the risk of injury.

For subject 1 and subject 2, we note that the succession of training loads is random; proving that the training program doesn't follow the principle of progressivity, for example for the subject 1 we see that the highest training load correspond to the first week.

\subsection{Comparison between the averages of the ratio (ALCL) over the 4 weeks}

According to figure 10 which represent the average of the ratio of the training load: acute / chronic, we note that for the first three footballers the training loads are higher compared to the others. 


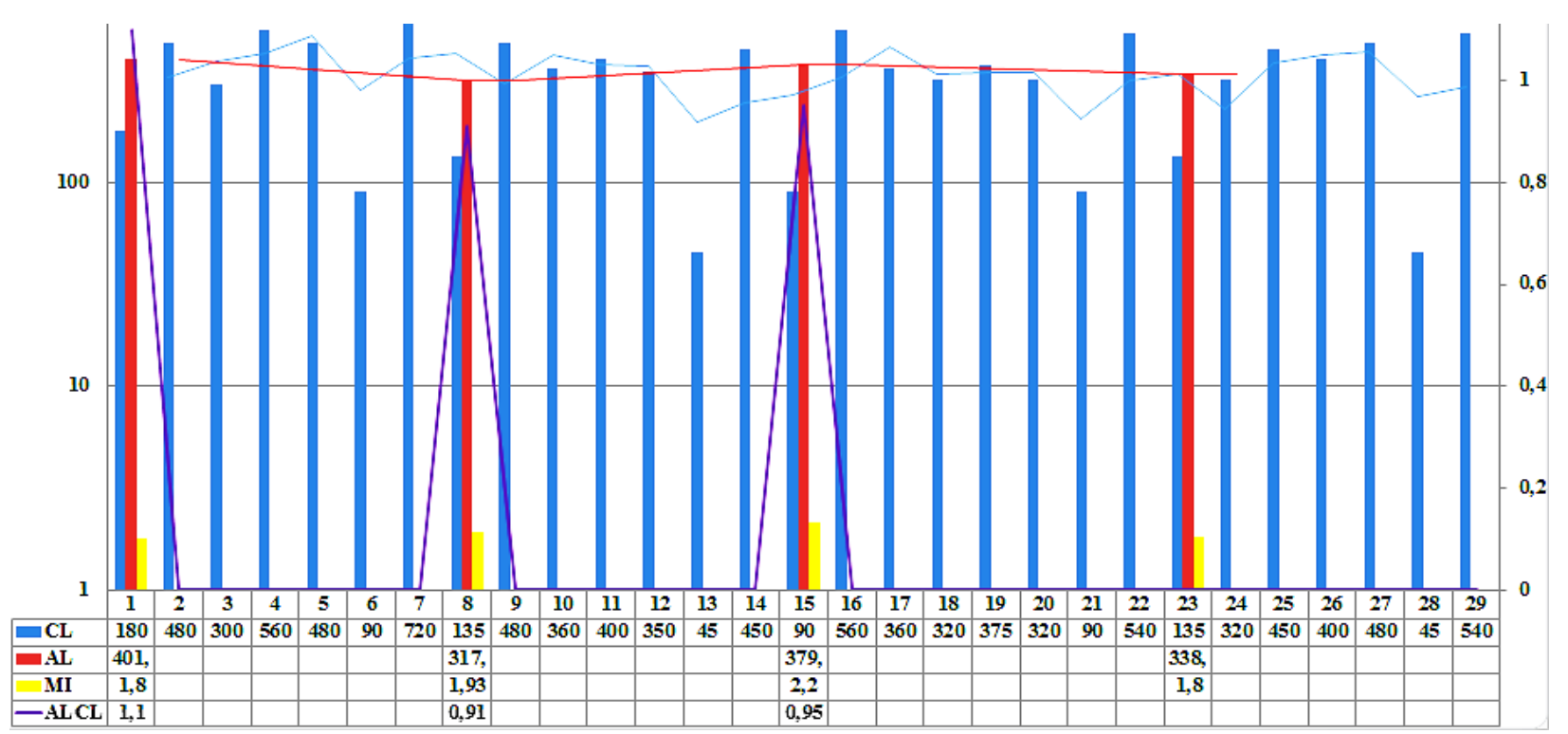

Figure 1. Monitoring training load for the footballer 1.

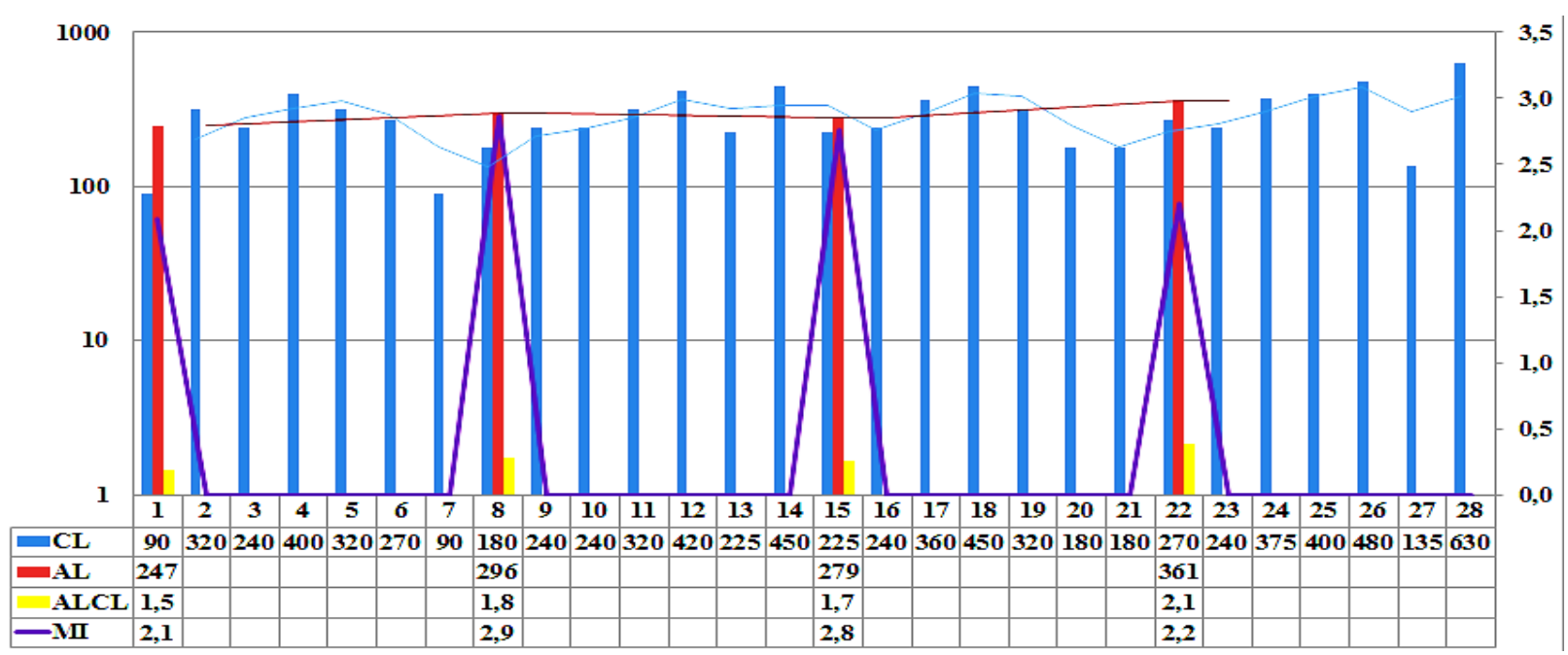

Figure 2. Monitoring training load for the footballer2.

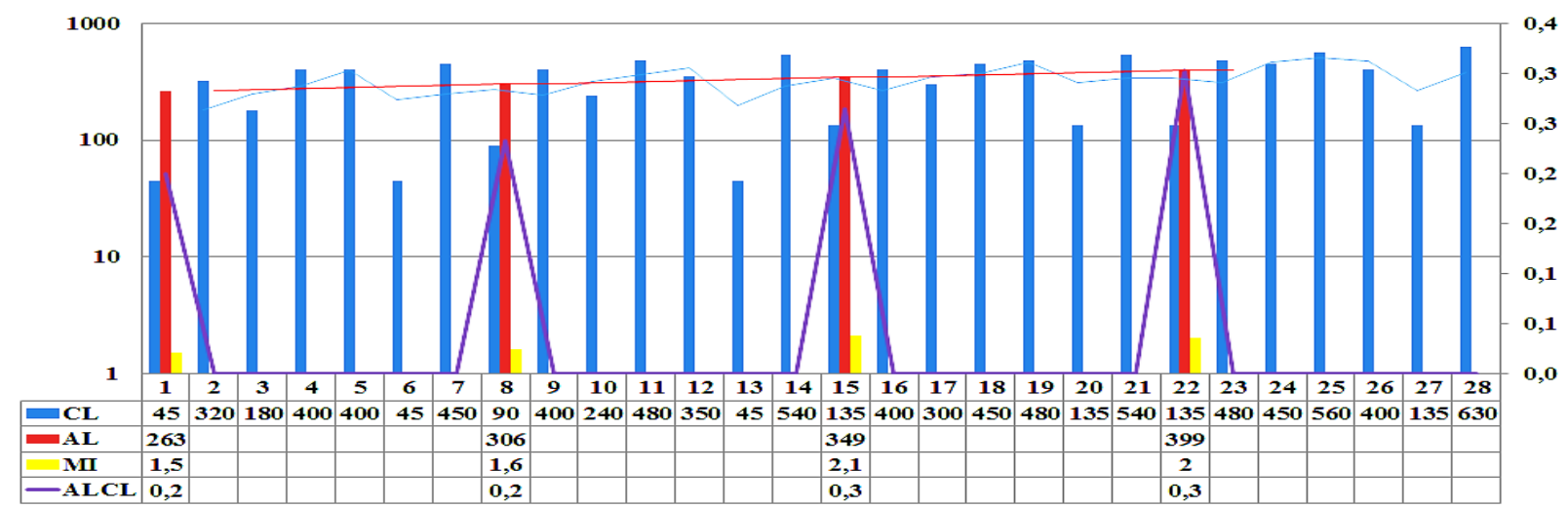

Figure 3. Monitoring training load for the footballer 3. 


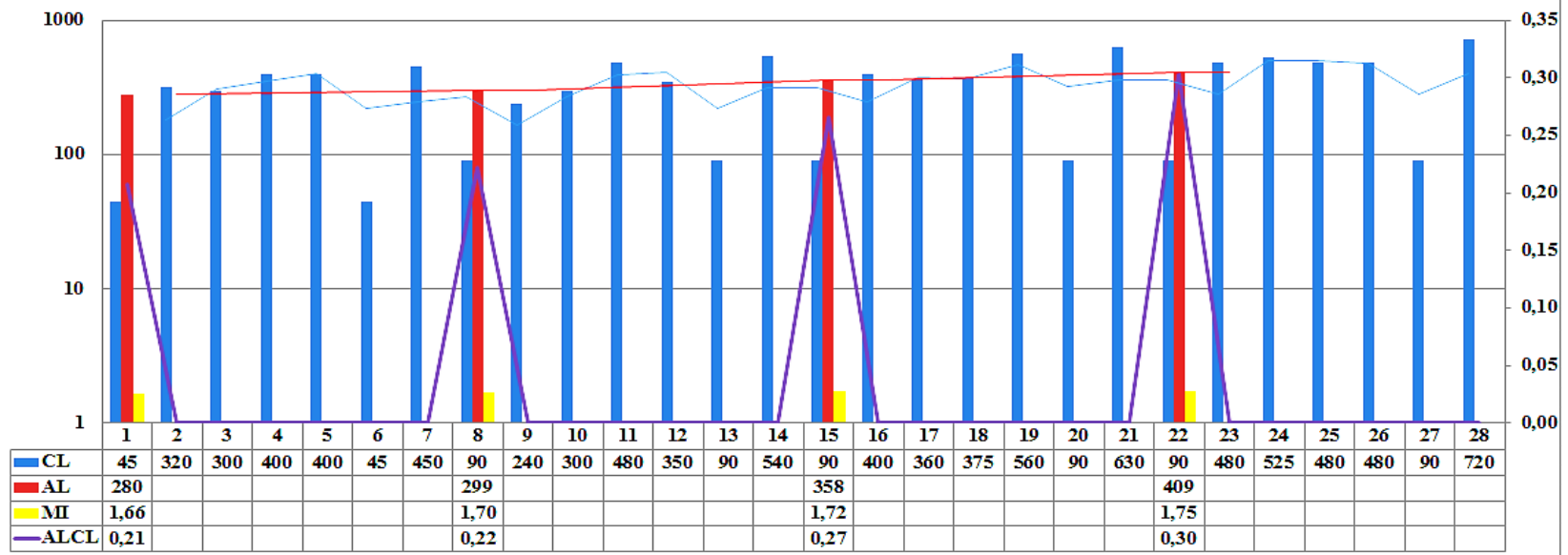

Figure 4. Monitoring training load for the footballer 4.

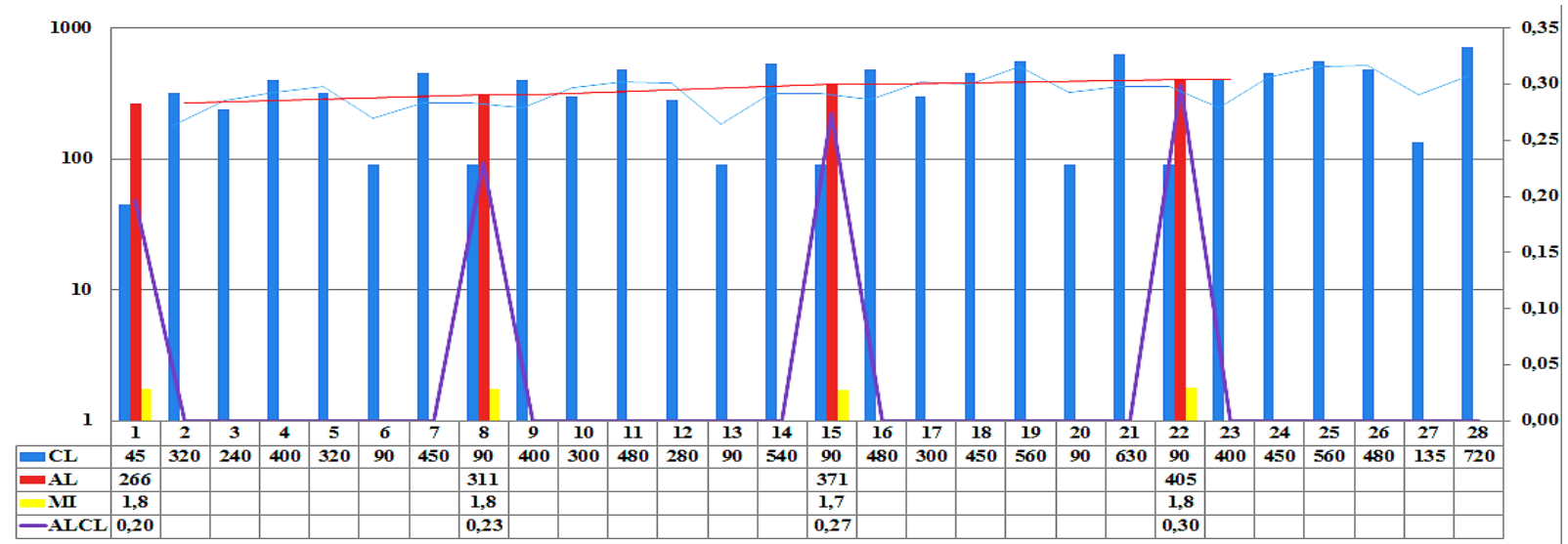

Figure 5. Monitoring the training load for the footballer 5.

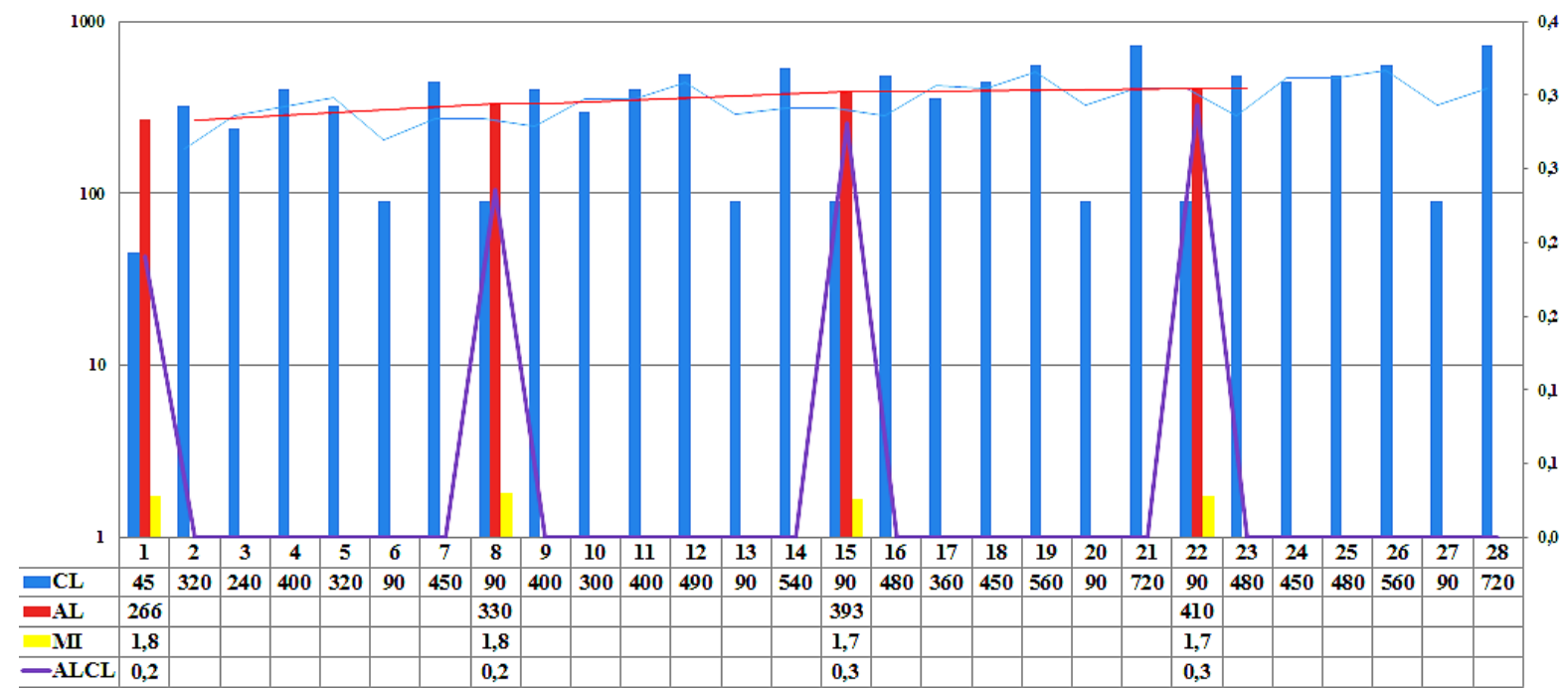

Figure 6. Monitoring the training load for the footballer 6 . 


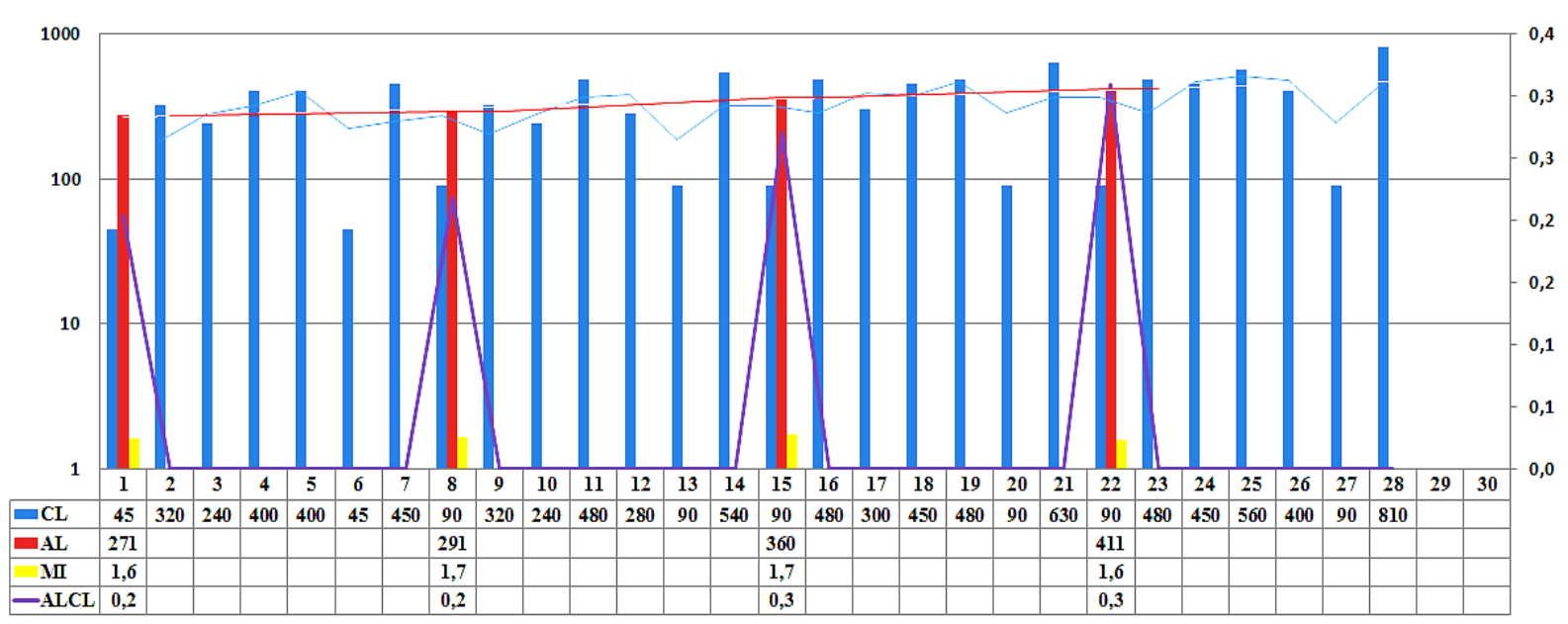

Figure 7. Monitoring the training load for the footballer 7.

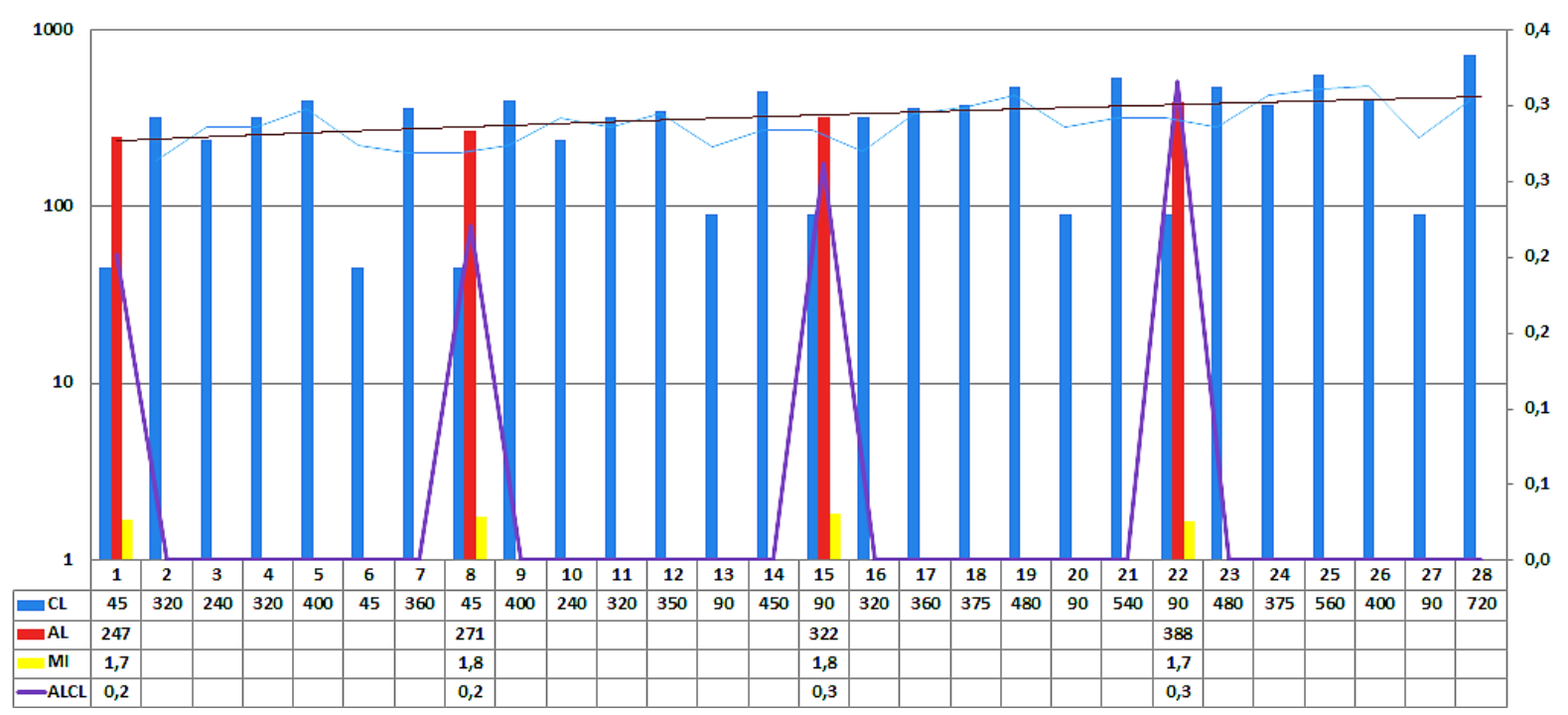

Figure 8. Monitoring the training load for the footballer 8.

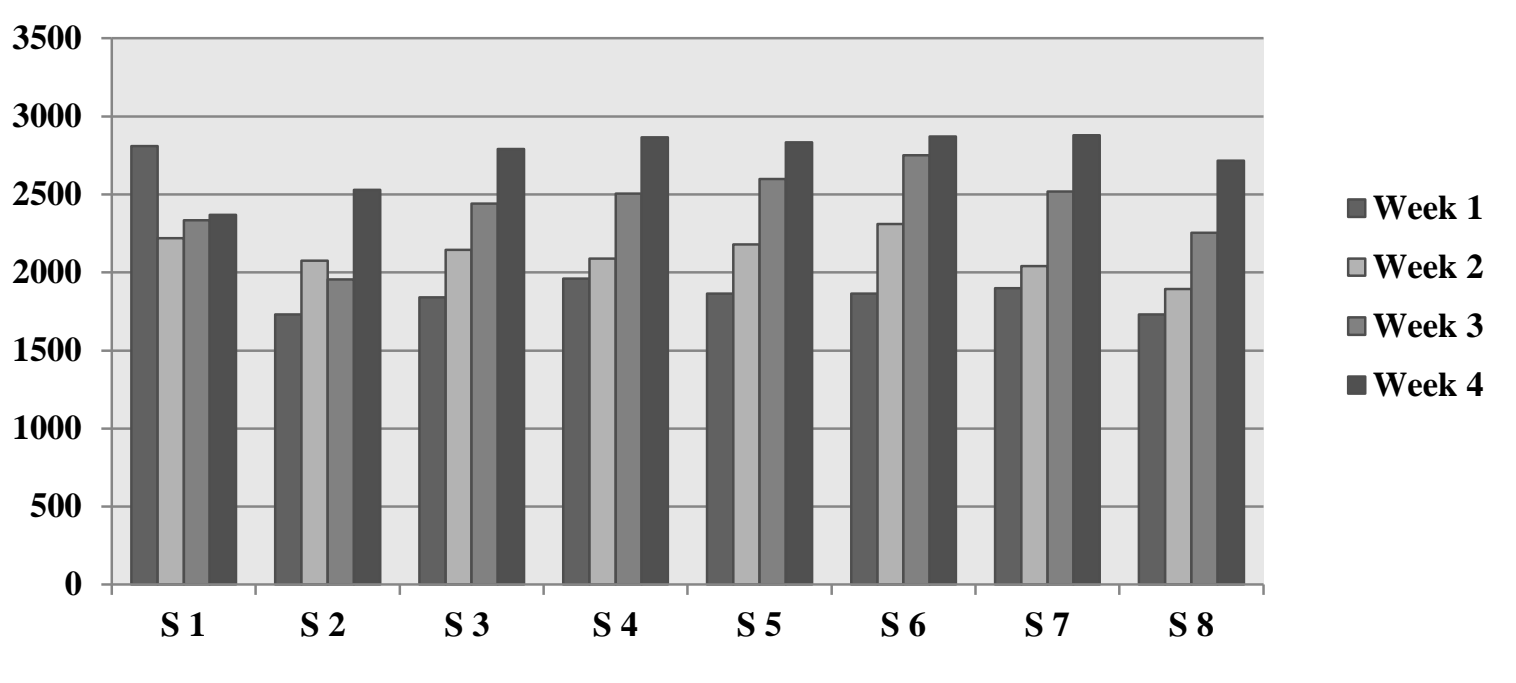

Figure 9. The sum of the training loads of the 8 footballers over 4 weeks. 


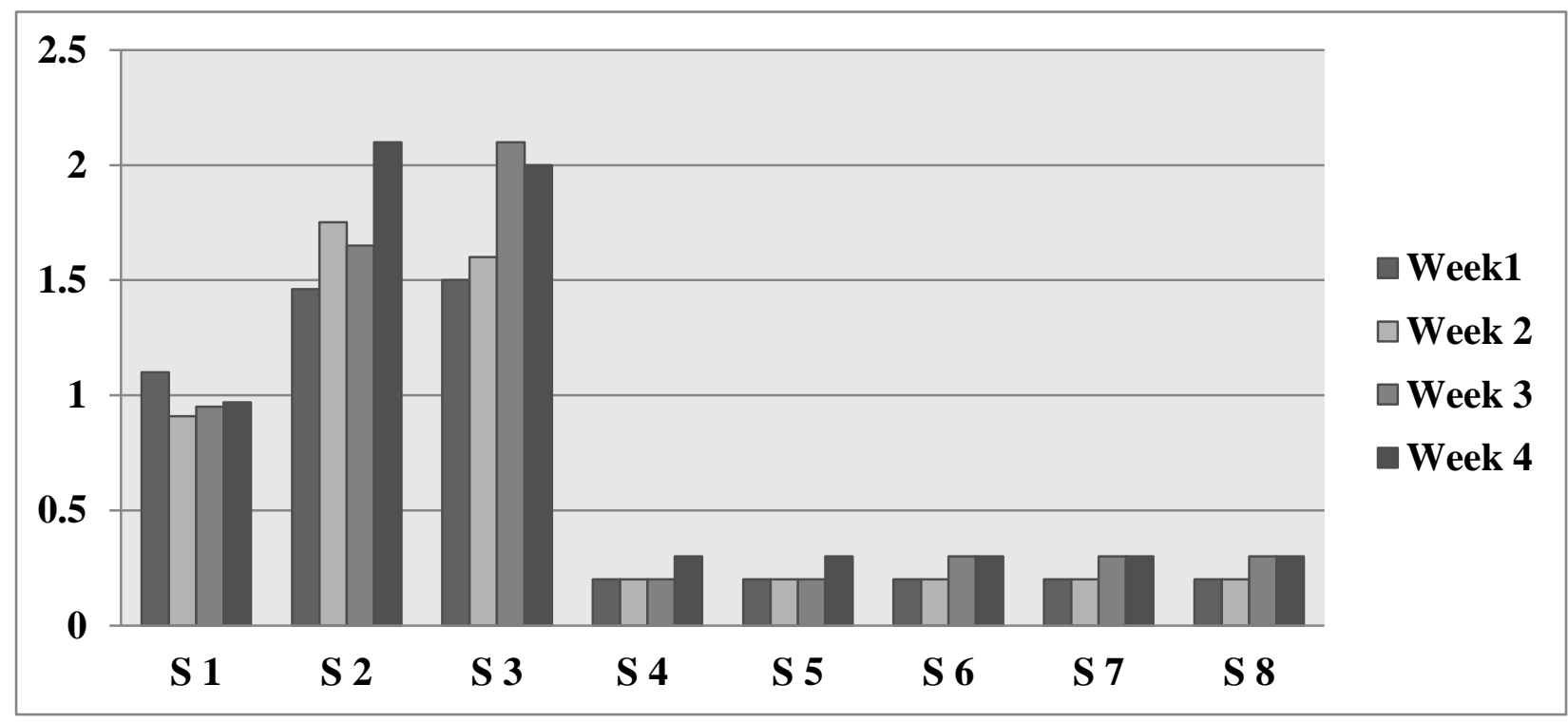

Figure 10. Comparison of the averages of the ratio of acute / chronic load over 4 weeks for the 8 footballers.

\section{Discussion}

Many Many studies have emphasized the importance of quantifying the training load to improve athletic performance [11-12-13-14-15-1617], and this was confirmed by the results of our study which shown that the RPE method is involved in the detection of the imperfections of a training program, especially those related to the state of freshness and fatigue that have a direct impact on the appearance of injuries during a football mesocycle.

Based on the results of the quantification of training load for the 8 footballers according to the figures from 1 to 8 , we note that in the majority of the cases, the AL is higher than the CL at the end of each week, which explains that at the end of each week the players and more and more tired, which makes him susceptible to develop an injury [5-18], and this result confirms that the training program delivered by the coach is not adapted to the athletes' requirements.

On the other hand, for the index of monotony that provides information on the negative adaptations of training and overtraining, we note that it present a high value among the majority of footballers (1.8UA $<$ MI <2.1UA), which, according to Foster, explains that a monotonicity index superior than 2 represents a significant risk factor for injury, and health problems related to overtraining [7].
According to figure 9, we noted that for subject 1 and subject 2, the succession of training loads is random, for example for the subject 1 the highest training load during the mesocycle appears in the first week, and this could be explained by the fact that the trainer did not take into account during the training program the principle of progressivity [10-5]. The risk of injury is minimized when load variations from one week to another remain less than $10 \%$ ( $8 \%$ risk of injury). On the other hand, with weekly variations in the order of $15-20 \%$, the risk of injury increases between $20-25 \%$ and increases gradually to reach nearly $50 \%$ when the variation of the load is massive [10]

According to figure 10, for the first 3 footballers, the load is higher compared to the others $(0.9$ $<$ ALCL $<2.1$ ), which explains why they are more exposed to injuries, same result for the other subjects because their RCAC is less than 0.8 which means that these footballers are not in a state of freshness which is defined by a ratio ALCL between 0,8 and 1 [5].

Based on several studies on football $[19,20]$, which showed that when CE values during pre-competitive periods reach values between (2300-2900) AU, there is a strong possibility that players are exposed to injuries, feelings of fatigue and especially to a decline in performance during the competition period.

Finally, since the RPE method is an effective evaluation tool for the monitoring training loads, it has its limitations, and takes into account in a large part the intuition of each participant about his 


\section{Zeghari Lotfi et al.,/2019}

training. However, an inexperienced athlete will find it more difficult to estimate the exact difficulty experienced during training and games [21].

\section{Conclusion}

The monitoring training load help to better conceptualize the adaptations of the athlete to the training, and also allows the prediction of the performance. Our study has shown that the use of the RPE method not only prevents injuries, but also better planned training sessions according to preestablished requirements, and to avoid the improvisation of loads randomly. And from here another study according to a longitudinal approach is desirable in order to study the impact of the quantification of the training load on the performance.

\section{References}

[1] Hägglund, Martin, Markus Waldén, and Jan Ekstrand, Injury incidence and distribution in elite football-a prospective study of the Danish and the Swedish top divisions, Scandinavian Journal of Medicine \& Science in Sports 15 (2005) 21-28.

[2] A. Ben Belgith, S. Ahmaidi, P. Maille, P. Noirez, F.D. Desgorces, Quantification de la charge d'entraînement imposée au footballeur professionnel en phase de réhabilitation athlétique post-blessure, Science \& Sports 27 (2012) 169-174.

[3] Meeusen R, Duclos M, Foster C, Fry A, Gleeson $M$, Nie-Man D,et al. Prevention, diagnosis and treatment of the overtraining syndrome: joint consensus statement of the European College of Sport Science and the American College of Sports Medicine, Medicine and Science in Sports and Exercise, 45 (2013) 186-205.

[4] S.L. Halson, Monitoring training load to understand fatigue in athletes, Sports Medicine, 44 (2014) 139-147.

[5] Tim J Gabbett, Billy T Hulin, Peter Blanch, Rod Whiteley, High training workloads alone do not cause sports injuries: how you get there is the real issue, British Journal of Sports Medicine, 50 (2016) 444-445.
[6] Vladimir Nikolaevič Platonov, L'entraînement sportif, théorie et méthodologie Broché - 1 janvier, Revue EPS (1988)

[7] A. Sedeaud, J.M. Sène, N. Krantz, G. Saulière, I. Moussa, J.F. Toussaint, L'importance de la quantification de la charge d'entraînement : exemple d'un modèle; The importance of quantifying training loads: A model example, Science \& Sports 33 (2018) 22-32.

[8] Gunnar Borg, Borg's perceived exertion and pain scales. Human kinetics, 1998.

[9] C. Foster, Monitoring training in athletes with reference to overtraining syndrome, Medicine and Science in Sports and Exercise 30 (1998) 1164-1168.

[10] Torbjørn Soligard, Martin Schwellnus, JuanManuel Alonso, Roald Bahr, Ben Clarsen, H Paul Dijkstra, Tim Gabbett, Michael Gleeson, Martin Hägglund, Mark R Hutchinson, Christa Janse van Rensburg, Karim M Khan, Romain Meeusen, John W Orchard, Babette M Pluim, Martin Raftery, Richard Budgett, Lars Engebretsen, How much is too much? (Part 1) International Olympic Committee consensus statement on load in sport and risk of injury, British Journal of Sports Medicine, 50 (2016) 1030-1041.

[11] E.W. Banister, T.W. Clavert, M.V. Savage, and T. Bach, A systems model of training for athletic performance, Australian Journal of Sports Medicine, 7 (1975) 57-61.

[12] D.D. Brown, Pulmonary responses to exercise and training. In: Exercise and Sport Science. W.E. Garrett and D.T. Kirkendall, eds. Philadelphia: Lippincott, Williams and Wilkins, 2000. pp. 117-134.

[13] T. Busso, C. Denis, R. Bonnefoy, A. Geyssant, and J.R. La- Cour, Modeling of adaptations to physical training by using a recursive least squares algorithm, Journal of Applied Physiology, 82 (1997) 1685-1693.

[14] J.R. Fitz-Clarake, R.H. Morton, and E.W. Banister, Optimizing athletic performance by influence curves, Journal of Applied Physiology, 71 (1991) 1151-1158.

[15] C. Foster, and M. Lehmann, Overtraining syndrome. In: Running Injuries. G. Guten, ed. 
Orlando: W.B. Saunders, Co., 1997. pp. 173188.

[16] R.H. Morton, J.R. Fitz-Clarke, E.W. Banister, Modeling human performance in running. Journal of Applied Physiology, 69 (1990) 11711177.

[17] I. Mujika, T. Busso, L. Lacoste, F. Barale, A. Geyssant, J.C. Chatard, Modeled responses to training and taper in competitive swimmers, Medicine \& Science in Sports \& Exercise, 28 (1996) 252-258.

[18] C. Foster, J.A. Florhaug, J. Franklin, L. Gottschall, L.A. Hrovatin, S. Parker, P. Doleshal, C. Dodge, A new approach to monitoring exercise training, The Journal of Strength \& Conditioning Research, 15 (2001) 109-115.

[19] E. Rampinini, A.J. Coutts, C. Castagna, R. Sassi, F.M. Impellizzeri, Variation in top level soccer match performance, International Journal of Sports Medicine, 28 (2007) 1018-1024.

[20] F.M. Impellizzeri, E. Rampinini, S.M. Marcora, Physiological assessment of aerobic training in soccer, Journal of Sports Sciences 23 (2005) 583-592.

[21] Alexandre Dellal, Karim Chamari, Del P. Wong, Said Ahmaidi, Dominique Keller, Ricardo Barros, Gian Nicola Bisciotti \& Christopher Carling, Comparison of physical and technical performance in European soccer match-play: FA Premier League and La Liga, European Journal of Sport Science 11 (2011) 51-59.

\section{Funding}

This study was not funded by any grant

\section{Acknowledgements}

The authors would like to thank every participant for his effort and time.

\section{Conflict of interest}

None of the authors have any conflicts of interest to declare.

\section{Informed consent}

All participants gave written informed consent to participate in this study.

\section{About The License}

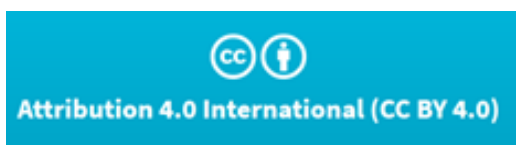

The text of this article is licensed under a Creative Commons Attribution 4.0 International License 